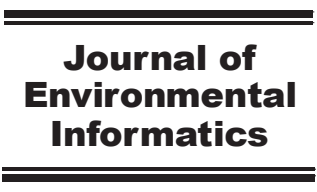

www.iseis.org/jei

\title{
Integration of CFD-Based Virtual Sensors to A Ubiquitous Sensor Network to Support Micro-Scale Air Quality Management
}

\author{
J. H. Woo ${ }^{1}$, S. M. An, ${ }^{2}$, K. Hong ${ }^{1}$, J. J. Kim³ , S. B. Lim, H. S. Kim4, and J. H. Eum ${ }^{5}$ \\ ${ }^{1}$ Division of Interdisciplinary Studies, Konkuk University, Seoul 143-701, Korea \\ ${ }^{2}$ Housing \& Land Research Division, Korea Research Institute for Human Settlements, Anyang 431-712, Korea \\ ${ }^{3}$ Department of Environmental Atmospheric Sciences, Pukyong National University, Pusan 608-737, Korea \\ ${ }^{4}$ Department of Internet and Multimedia Engineering, Konkuk University, Seoul 143-701, Korea \\ ${ }^{5}$ Department of Landscape Architecture, Keimyung University, Daegu 705-701, Korea
}

Received 31 Janunary 2013; revised 27 January 2014; accepted 26 February 2014; published online 10 April 2016

\begin{abstract}
As a city is urbanized, its landscape becomes more complex owing to the construction of high-rise buildings. The small scale wind-field in an urban district may change frequently owing to the complex terrain, the diverse land use, and high-rise buildings. It also leads to dynamic changes in the air pollution in that area. Conventional urban-scale air quality management systems, however, are unable to effectively manage detailed aspects of such changes. In this study, we set up a micro-scale air quality management system (MAMS) testbed over Konkuk University, Seoul, Korea. A wireless sensor network and a CFD modeling data management system were combined to support the MAMS sensor service. The sensor-based monitoring system showed reasonably good performance for temperature, humidity, and carbon dioxide from inter-comparison studies against conventional large format analyzers. However, the real-world application of a sensor network for air quality monitoring has many limitations, such as limited installation points for 3-dimentional monitoring, limited power availability for continuous monitoring, and limited sensitivity to ambient concentrations. We therefore developed the concept of a "virtual sensor" to provide micro-scale personal air pollution information services, using a CFDbased air quality modeling system. Based on the information provided by the virtual sensors, we developed a futuristic air quality service of the MAMS application for the mobile platform. We found that the combination of CFD-based modeling data with a fast large volume data management system and a mobile visualization system will be a successful intermediate solution for a user-based air quality service before an actual ubiquitous sensor-based system is available to produce micro-scale environmental information for entire urban areas.
\end{abstract}

Keywords: USN, MAMS, monitoring network, air quality model, CFD, virtual sensor, mobile service

\section{Introduction}

As a definition, sensor is a device that detects some type of input and the sensors can be divided into two categories: real (physical) sensor and virtual sensor (Liu et al., 2009). A physical sensor responds to the physical environment such as digital thermometer, which converts the temperature into the readable digital voltage signal. On the other hand, virtual sensor, also known as soft sensor, smart sensor or estimators, estimates properties or conditions of environment using mathematical models rather than physical sensors, are used in place of the real sensors (Wilson, 1997). The concept of virtual sensor or virtual sensor network has widely introduced many research areas such as computer science (Hardy and Maroof, 19 99), microphone arrangement (Elliot and David, 1992), global

${ }^{*}$ Corresponding author. Tel.: +231 380 0114; fax: +231 3800470.

E-mail address: sm_an@krihs.re.kr (S. M. An).

ISSN: 1726-2135 print/1684-8799 online

(C) 2016 ISEIS All rights reserved. doi: 10.3808/jei.201500314 positioning (Hu et al., 2003), traffic management (Dailey and Cathey, 2006), remote sensing-based air quality estimating (Ung et al., 2009; Moussafir et al., 2013).

The urban environment is where an increasing share of the world's population resides, where most commercial energy is consumed, and where the impacts of pollution are felt the most. Rapid economic growth in urban Asia has attracted millions of rural residents to metropolitan environments (Guttikunda et al., 2003). Changing standards of living in the urban centers have fueled increasing energy demand often associated with unchecked emissions from automobiles, domestic heating, and small-scale industries. Asian urban centers, which are prone to air pollution, incur hundreds of millions of dollars in excess health care costs and economic damage (OECD, 2000). Presently, the urban air pollution problems in Asia are continuing to increase, and the air pollutants originating from urban regions are recognized as increasing sources of regionnal- and global-scale pollution (Streets et al., 2000).

The Seoul Metropolitan Area (SMA), which is located near the center of the Korean Peninsula, has been suffering from such air pollution problems. Regional air pollution transport 
from China as well as local pollution sources, such as thermal power plants and mobile sources, have also become major contributors to increasing human health issues in the urban SMA environments. Besides these problems, micro-scale air pollution, which lasts for minutes to hours and covers several kilometers, exist in the SMA. Two examples of micro-scale air pollution are fugitive dust from construction fields or the accidental release of hazardous pollutants. Unlike regional to local scale air pollution, which is a traditionally well-established research area in the SMA, micro-scale air pollution has rarely been studied. This is mainly because monitoring and modeling methods developed for larger scales are not appropriate for addressing the micro-scale phenomena. The need for more detailed information, however, has been increasing with the need for real-time emission estimation for public services like air quality information and with the increasing complexity of the urban building geography.

Therefore, micro-scale air monitoring and modeling systems need to be developed to improve our level of understandding of micro-scale air pollution, for providing better and more detailed public information services. For this study, we set up a micro-scale air quality management system (MAMS) testbed over Konkuk University, Seoul, Korea. A ubiquitous sensor-based monitoring network and a computational fluid dynamics (CFD)-based air quality modeling system that can produce a large amount of data were developed. Using the monitoring network, we monitored micro-scale air quality over the Konkuk University Complex (KUC) testbed to test the possibility of utilizing a ubiquitous sensor-based monitoring system.

The real-world application of sensor networks for air quality has many limitations, such as limited install points for 3-dimentional monitoring, limited power availability for continuous monitoring, and limited sensitivity to ambient concen-

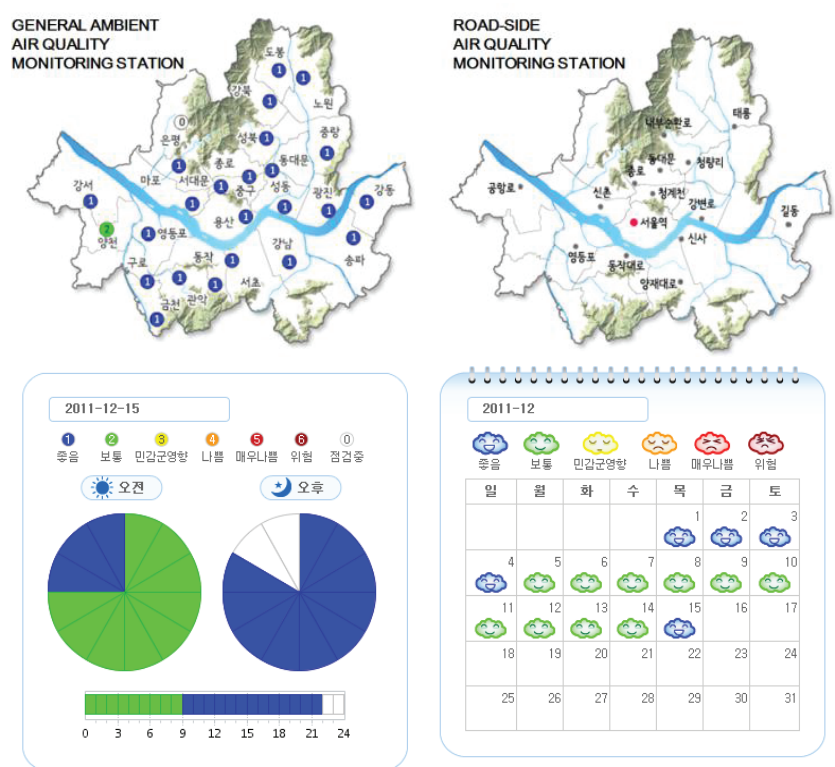

Figure 1. Monitoring stations in Seoul and Air Quality Clock/Calendar (Source: http://cleanair.seoul.go.kr). trations. Hence, in this study, we developed the concept of a "virtual sensor," which uses air quality modeling data instead of "real sensor" data for the anticipated monitoring locations for micro scale air quality. A CFD-based micro-scale air quality model was used to provide meteorological and air quality information on designed monitoring locations over the KUC testbed. Based on the information provided by the virtual sensors, we developed a futuristic air quality service of the MAMS application for the mobile platform. This study will offer a successful intermediate solution for user-based air quality service, before actual ubiquitous sensor-based systems that can produce micro-scale environmental information for entire urban areas are made available. Although many different pollutants are affecting various aspect of human health, we assumed the most urgent pollutant in Seoul would be fine particles because; 1) they could be emitted very regional (i.e. yellow dust) and very local (i.e. local fire), 2) they can seriously affect to human health based on their size and chemical composition, 3) they are relatively easy to detect and remove.

\section{Materials and Methods: Design of MAMS}

\subsection{Present Status of the Air Quality Management System in Seoul}

Currently, the air quality information infrastructure in Seoul is supported by 25 general ambient air monitoring stations and 14 roadside air monitoring stations, which provide hourly concentrations of 7 criteria air pollutants. The stations are operated by the Ministry of Environment (MOE) and the Seoul Metropolitan Government. Air quality information consists of pollutant concentrations and an Air Quality Index (AQI), and they are made available to the public through a web page. The locations of the 25 general ambient (circle) and 14 roadside (point) air quality monitoring stations in Seoul and two types of user-friendly air quality information are shown in Figure 1.

The present resolution of the monitoring network is not detailed enough to deal with micro-scale air pollution problems such as unexpected releases of air pollutants from construction fields or fires. In addition, existing monitoring systems are not adequate for micro-scale dispersion owing to complex dispersion patterns derived from high-rise buildings, whereas behaviors of air pollutants as well as air pollution are much more complicated at the micro-scale.

Several research efforts have tried to use sensor-based monitoring for environmental monitoring and/or management (Carotta et al., 2001; Kamionka et al., 2006; Woo et al., 2010). Woo et al. (2010) carried out perhaps the most recent study on micro-scale air quality in Seoul. They set up an initial form of a MAMS by utilizing technology fusions with Information Technology (IT). They also developed a GIS database for microscale domains in 3D and 2D. Moreover, a micro-scale emission inventory system was developped to support the MAMS. Yoo et al. (2010) set up a micro-scale air quality management testbed near Konkuk University. A ubiquitous sensor monitorring network, a high resolution emission database, and a CFD- 
based air quality modeling system were developed, and then applied to the testbed. A sensor data management system using wireless technology and a multi-modal scientific visualization module were combined in support of the management system.

Those efforts have introduced innovative new technologies to the environmental management area. However, the realworld application of those new technologies into environmental management has many limitations, as noted earlier (Ciciriello et al., 2006; Ma et al., 2008; Ung et al., 2001). Recently, Mead et al. (2013) proposed the capability of electrochemical sensors for gas-phase measurements such as $\mathrm{NO}, \mathrm{NO}_{2}$ and $\mathrm{CO}$. They built the state of the art electrochemical sensors at the parts-per-billion (ppb) level, which is a remarkable milestone in low-cost, high density sensor network study. However, although their ambition is to extend low-coast, high density sensor network philosophy until micrometeorology become available, building higher network densities in the urban with a huge number of sensors would be impractical in the short term as well as prohibitively expensive. This research, therefore, focuses mainly on "gap-filling" between the emerging needs and the real situation. The basic framework of the MAMS and functional designs of its components are listed in the next section.

\subsection{Design of MAMS Framework}

MAMS is a need-based monitoring and modeling system to meet public needs for air quality information and to complement the limitations of existing monitoring and modeling systems. Figure 2 schematically shows how the MAMS produces micro-scale environmental information for public needs. The basic function of the MAMS is to produce air quality data by both ubiquitous sensor network (USN)-based monitoring and CFD-based modeling. Owing to some limitations of current sensor networks to produce air quality data, however, the concept of the virtual sensor network based on CFD modeling and a 3D GIS database is introduced.

The entire structure of the MAMS data management system consists of three layers. The first layer involves air quality data production based on the sensor network. The second layer is the middleware layer that provides functionalities such as management of data and resources. The last layer is for visualization by using data stored in a repository or using real time streaming data to effectively provide a useful representation of the environmental information for users. Each middleware component and service will be described in the following sections.

\subsection{CFD-Based Air Quality Modeling for Virtual Sensor Network}

Micro-scale air quality varies dynamically over short times and small spaces. Understanding micro-scale air quality of specific area by depending solely on monitoring would be difficult, because the monitoring cannot offer the whole air quality information of the entire area. The air quality model-

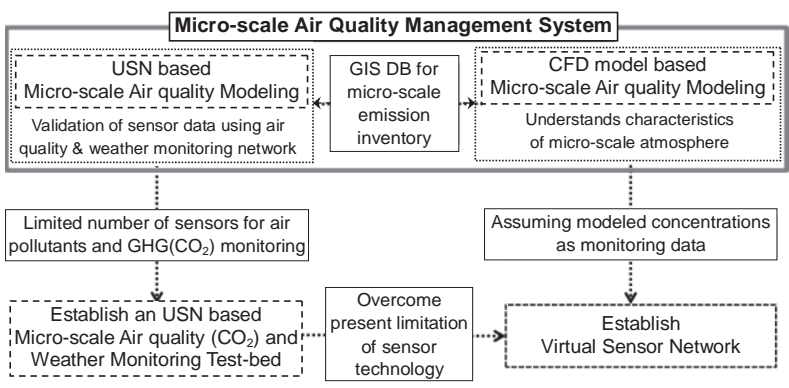

Figure 2. Schematic diagram of the MAMS.

ing technique, therefore, should be very beneficial to incorporate. A computational fluid dynamics (CFD) air quality model was chosen because of its suitability for representing complex advection and dispersion patterns in micro-scale domain. The model can represent a complex building geography, not as simple parameters such as the roughness length scale, but by solving fluid dynamics equations. Navier-Stokes equations are the basic governing equations for a viscous, heat conducting fluid, and can be simply written as:

$\overrightarrow{u_{t}}=-(\vec{u} \cdot \nabla) \vec{u}+\nabla \cdot(v \nabla \vec{u})-\frac{1}{\rho} \nabla p+\vec{f}$

$\nabla \cdot \vec{u}=0$

where $\vec{u}$ is the fluid vector $(u, v, w)$ component, $\overrightarrow{u_{t}}$ is the differential of the fluid vector, $p$ is the pressure, $\rho$ is the density, $v$ is the viscosity, and $f$ is the external force. The CFD model used in this study considers a three-dimensional, nonhydrostatic, non-rotating, and incompressible airflow system, which was developed and validated by Kim and Baik (2010). The model includes the $\mathrm{k}-\varepsilon$ turbulence closure scheme based on renormalization group (RNG) theory, and employs wall functions at the solid surfaces.

\subsection{Testbed and 3D GIS in Support of MAMS}

The testbed for the micro-scale air quality management system was set over the $1.5 \times 1.5 \mathrm{~km}$ domain around the Konkuk University Complex (KUC), which is located on eastern part of Seoul metropolitan area, South Korea (Figure 3(a)). KUC domain includes modern residential/commercial buildings, a hospital, a university campus, and subway stations. The MAMS can be connected with a GIS database to view the overall array of components of the KUC, such as buildings, hills, water, roads, and subway stations. This helps understand the dispersion of air pollutants and complex wind paths resulting from building blocking effects, to be applied to a CFD dispersion model and the visualization module as a base-map of the KUC. GIS layers were used to set up a sensor deployment plan. Grid maps of 100 and $200 \mathrm{~m}$ sizes were generated on the top of the $2 \mathrm{D}$ digital map by considering a Zigbee sensor's wireless network range. The resulting GIS structures with grid maps enabled us to plan the deployment of sensors, co- 

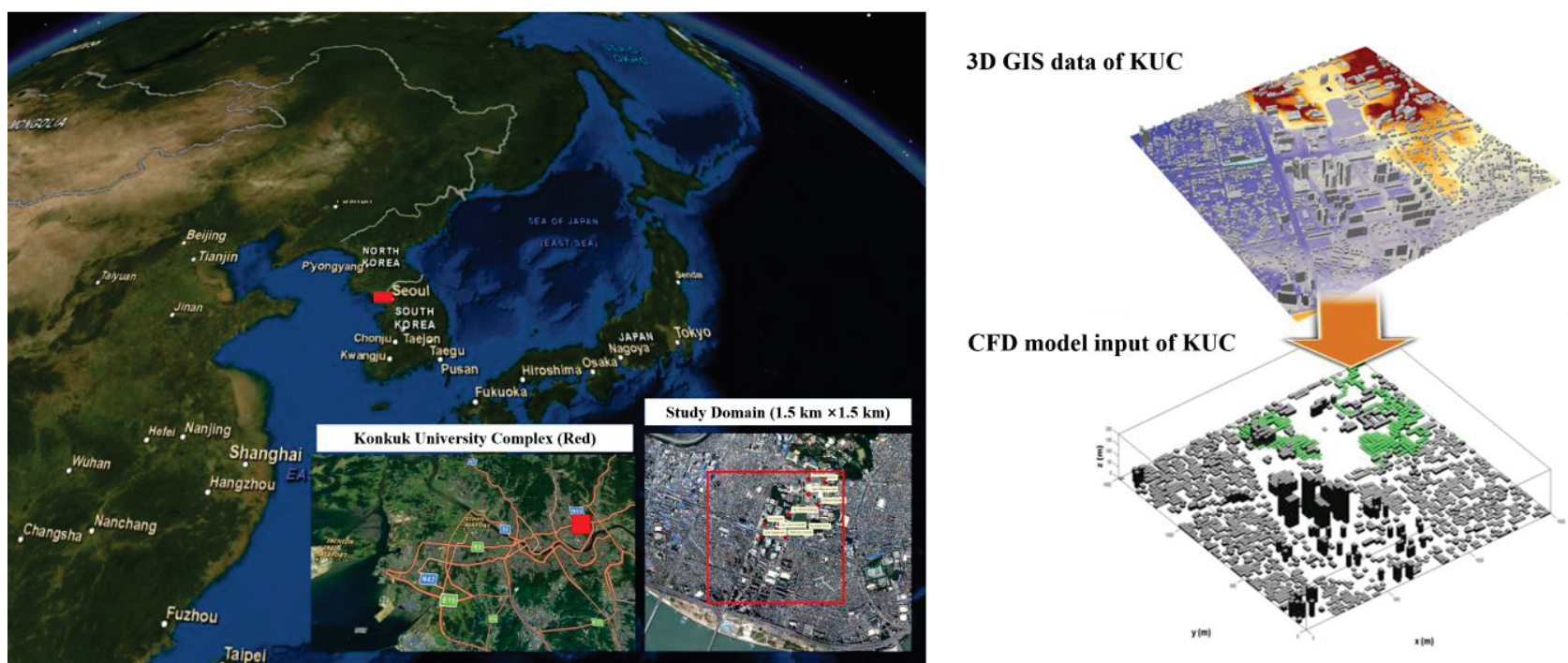

Figure 3. Geographical location of the testbed and used GIS data: Konkuk University Complex testbed for micro-scale air quality management system (MAMS), and 3D Buildings GIS data for virtual sensor network and the derived CFD modeling input.

nsidering landscape and structures. We then established a 3D GIS map with height information based on the 2D map to attach sensors vertically in and near Konkuk University. The established 3D GIS map was used as input data for performing CFD air quality modeling (Figure 3(b)) and for visualizing the CFD output data (Figure 13(b)). In CFD modeling, results will be employed on 2D and 3D GIS maps with the actual dimensions of the building structures. CFD modeling output, therefore, will be used to study the dispersion of pollutants from a more realistic urban area (Guttikunda et al., 2003).

\subsection{CFD Modeling and Data Extraction for Virtual Sensor Network}

To test the usefulness of the virtual sensors, we ran the CFD model over the KUC modeling domain. The CFD model

(a)

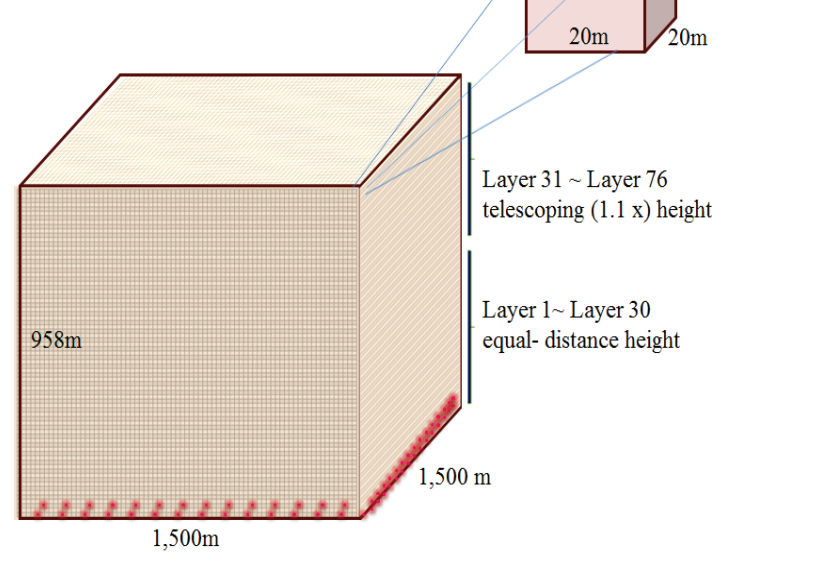

follows cubic as a meshing algorithm, which is easy and clear to discretize an urban geometry. The modeling domain covers $1500 \times 1500 \times 958 \mathrm{~m}$ in the $\mathrm{x} \times \mathrm{y} \times \mathrm{z}$ directions, respectively, with $10 \mathrm{~m}$ horizontal grid resolution. The number of grids for the air pollution field is 1,710,000 cells $(150 \times 150 \times 76)$ (note that the vertical grid spacing after $200 \mathrm{~m}$ height above ground is variable) as seen in Figure 4(a). Five air quality concentration criteria pollutants (Table 1), modeling time, location, and additional information were extracted from CFD_OUTP UT, CFD_INDEX, and DOMAIN_METADATA for converseon into virtual sensor feature objects (Figure 4(b)).

Following air quality concentration criteria pollutants: carbon monoxide (CO), nitrogen dioxide $\left(\mathrm{NO}_{2}\right)$, particulate matter $\left(\mathrm{PM}_{10}\right)$, sulphur dioxide $\left(\mathrm{SO}_{2}\right)$ and volatile organic compound (VOC) were extracted from the CFD modeling result

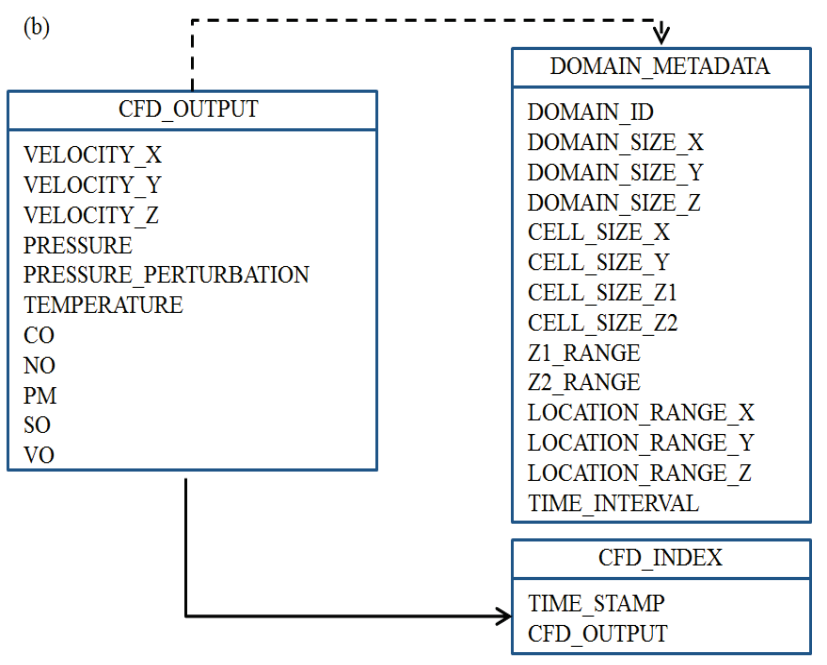

Figure 4. MAMS Virtual sensor network: (a) CFD model array of the KUC testbed $(150 \times 150 \times 76)$; (b) conceptual diagram of the virtual sensor network database management system. 
Table 1. Five Air Quality Concentration Criteria Pollutants for Virtual Sensor Network

\begin{tabular}{llllll}
\hline Sensor Type & $\mathrm{CO}$ & $\mathrm{NO}_{2}$ & $\mathrm{PM}_{10}$ & $\mathrm{SO}_{2}$ & $\mathrm{VOC}$ \\
\hline Pollutant & carbon monoxide & nitrogen dioxide & particulate matter & sulphur dioxide & volatile organic compound \\
Unit & $\mathrm{ppm}$ & $\mathrm{ppm}$ & $\mu \mathrm{g} / \mathrm{m}^{3}$ & $\mathrm{ppm}$ & $\mathrm{ppm}$ \\
Type/Precision/Scale & double/5/2 & double/5/2 & double/5/2 & double/5/2 & double/5/2 \\
\hline
\end{tabular}

and recomposed to virtual sensors as the format in Table 1.

Arithmetically, the testbed CFD model can be converted to $1,710,000$ virtual sensors, but we extracted only 556 virtual sensors because of two reasons: one is most of sensors have redundant values or far away from human living places, and the other is many overlaid sensors can disturb viewer's eyes which would deteriorate visual interpretation and hence interrupt user controls or relating experiences. 556 virtual sensors (498 sensors are on the ground and 58 sensors are on the aerial space (over the ground), which is close to high rise residential building walls) are for the place where residents can normally access.

\subsection{Sensor-based Monitoring Network and Air Quality Data Management System}

The concept of a ubiquitous sensor network (USN) was used to realize micro-scale monitoring. USN is the Korean brand name for a wireless sensor network (WSN) and its related technologies (Figure 5(a)). A USN is composed of wired and wireless networks including sensors, instruments, electronic tags/readers, middleware, and an application platform. It manages real-time information from the network and enables monitoring of environmental information from multiple sensors in a micro-scale region (Woo et al., 2010). An environment monitoring and modeling system has to deal with a large volume of data and various types of sensors. This would cause difficulties in data sharing among different systems and users. To resolve this problem, we need to abstract it to a standard sensor model. Our system uses two sensor model languages, namely SensorML (Open GIS $\left.{ }^{\circledR}, 2007 a\right)$ and Observation and Measurement (O\&M) (Open GIS $\left.{ }^{\circledR}, 2007 b\right)$, for standard sensor modeling and observation and measurement data model- ing; both languages were developed by the Open Geospatial Consortium (OGC). Figure 5(b) describes the USN sensor data model of the AirScope System. AirScope is a micro scale air quality monitoring system, which covers local environments of a ubiquitous air quality sensor network (Woo et al, 2010). The model consists of SENSOR_DATA, SENSORML, O\&M, SENSOR_STATUS, and SENSORML_INDEX. SENSOR_DATA describes the data that are produced by the sensors. The produced data are used directly in the real-time monitoring system and are encoded into O\&M and SENSOR_ STATUS, which is used for resource management. O\&M contains real-data values such as TIME_STAMP, RESULT, and references to SENSORML. SENSORML includes meta-information of O\&M. SENSORML and O\&M are XML documentts and are managed by Berkeley XML DB. SENSORML_INDEX has information about SENSORML_ID, O\&M_ID, and SENSOR_ID.

\section{Results and Discussion}

\subsection{Environmental Monitoring Using a Sensor Network}

Environmental sensors, which monitor temperature, humidity, $\mathrm{CO}_{2}, \mathrm{CO}$, and $\mathrm{PM}_{10}$ signals, were installed at 8 sites in the KUC testbed (Table 2). The data collected from the CO and $\mathrm{PM}_{10}$ sensors were not used in this analysis because the data did not satisfy the normal detection range of ambient monitoring instruments. The sensors from the wireless network were connected to a gateway that receives the data from the sensor and transfers it to the server every second. The collected data are stored in the repository server (AirScope). Figure 6 shows the installed USN monitoring stations, their locations, sensors in the monitoring stations and automatic weather station (AWS) at the KUC domain. The gateway (MTC-GM

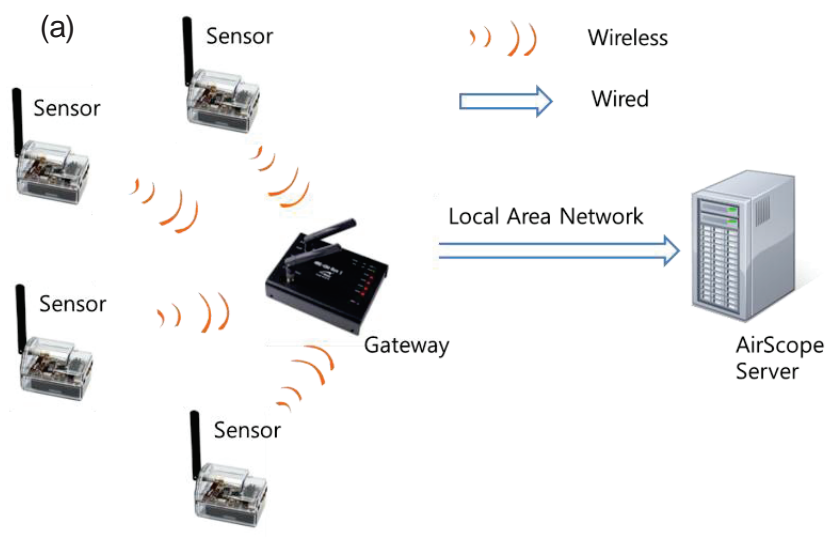

(b)

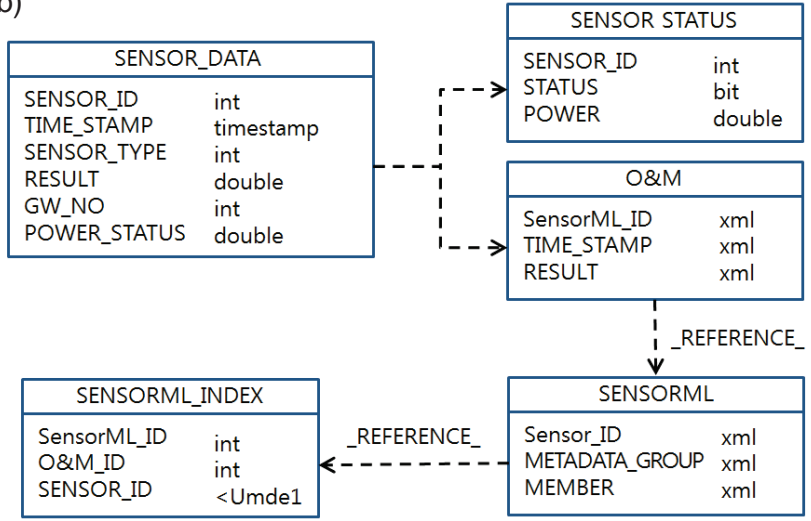

Figure 5. MAMS USN sensor network: (a) USN-based monitoring infrastructure; (b) conceptual diagram of the USN database (real-data) management system. 
Table 2. USN and AWS Monitoring Stations Installed at the KUC domain

\begin{tabular}{|c|c|c|c|c|}
\hline Monitoring sites & Station Type & Symbol & Location (Lat./Lon.) & Sensor height (AGL*/ASL**) \\
\hline Iluhun & USN & (1) & $37^{\circ} 32^{\prime} 41.5270^{\prime \prime} \mathrm{N} 127^{\circ} 04^{\prime} 46.9504^{\prime \prime} \mathrm{E}$ & $15.5 \mathrm{~m} / 35.3 \mathrm{~m}$ \\
\hline New Millennium Hall & USN & (2) & $37^{\circ} 32^{\prime} 37.0318^{\prime \prime} \mathrm{N} 127^{\circ} 04^{\prime} 39.2235^{\prime \prime} \mathrm{E}$ & $66.4 \mathrm{~m} / 84.7 \mathrm{~m}$ \\
\hline Liberal Art Building & USN & (3) & $37^{\circ} 32^{\prime} 32.8157^{\prime \prime} \mathrm{N} 127^{\circ} 04^{\prime} 43.9323^{\prime \prime} \mathrm{E}$ & $22.3 \mathrm{~m} / 31.0 \mathrm{~m}$ \\
\hline $\begin{array}{l}\text { International } \\
\text { Dormitory }\end{array}$ & USN & (4) & $37^{\circ} 32^{\prime} 23.0951^{\prime \prime} \mathrm{N} 127^{\circ} 04^{\prime} 38.2948^{\prime \prime} \mathrm{E}$ & $24.6 \mathrm{~m} / 42.4 \mathrm{~m}$ \\
\hline Veterinary Hospital & USN & (5) & $37^{\circ} 32^{\prime} 20.7666^{\prime \prime}$ N $127^{\circ} 04^{\prime} 28.7255^{\prime \prime} \mathrm{E}$ & $20.6 \mathrm{~m} / 35.4 \mathrm{~m}$ \\
\hline Law School Building & USN & (6) & $37^{\circ} 32^{\prime} 29.2560^{\prime \prime} \mathrm{N} 127^{\circ} 04^{\prime} 30.2112^{\prime \prime} \mathrm{E}$ & $20.7 \mathrm{~m} / 38.9 \mathrm{~m}$ \\
\hline Indu.-Univ. Coop BD & USN & (7) & $37^{\circ} 32^{\prime} 23.7599 " \mathrm{~N} 127^{\circ} 04^{\prime} 24.6681^{\prime \prime} \mathrm{E}$ & $32.6 \mathrm{~m} / 47.4 \mathrm{~m}$ \\
\hline KU Hospital & USN & (8) & $37^{\circ} 32^{\prime} 25.8446 " \mathrm{~N} 127^{\circ} 04^{\prime} 19.2140 " \mathrm{E}$ & $17.5 \mathrm{~m} / 31.3 \mathrm{~m}$ \\
\hline Indu.-Univ. Coop BD & AWS & (a) & $37^{\circ} 32^{\prime} 22.3651 " \mathrm{~N} 127^{\circ} 04^{\prime} 24.9326^{\prime \prime} \mathrm{E}$ & $32.6 \mathrm{~m} / 38.9 \mathrm{~m}$ \\
\hline
\end{tabular}

*AGL: above ground level, **ASL: above sea level.

1200, Maxfor Co.) of sensor node was installed at site 7.

At first two years (2009 2010), USN monitoring stations shows a robustness but its robustness slowly decreased because the sensors and the gateway is weak at the outdoor conditions such as dust and extreme weather. As seen in Figure 7, major reasons of AirScope data management failure are gateway disorder and sensors disorder.

\subsection{Sensor Validation}

For USN sensor data validation, both meteorological sensor (for temperature and humidity, Figure 6(d)) data were compared with AWS data, applying regression fitting for the 8 monitoring sites. The equipment and specifications of the USN sensor and AWS installed in the KUC domain are shown in Table 3.
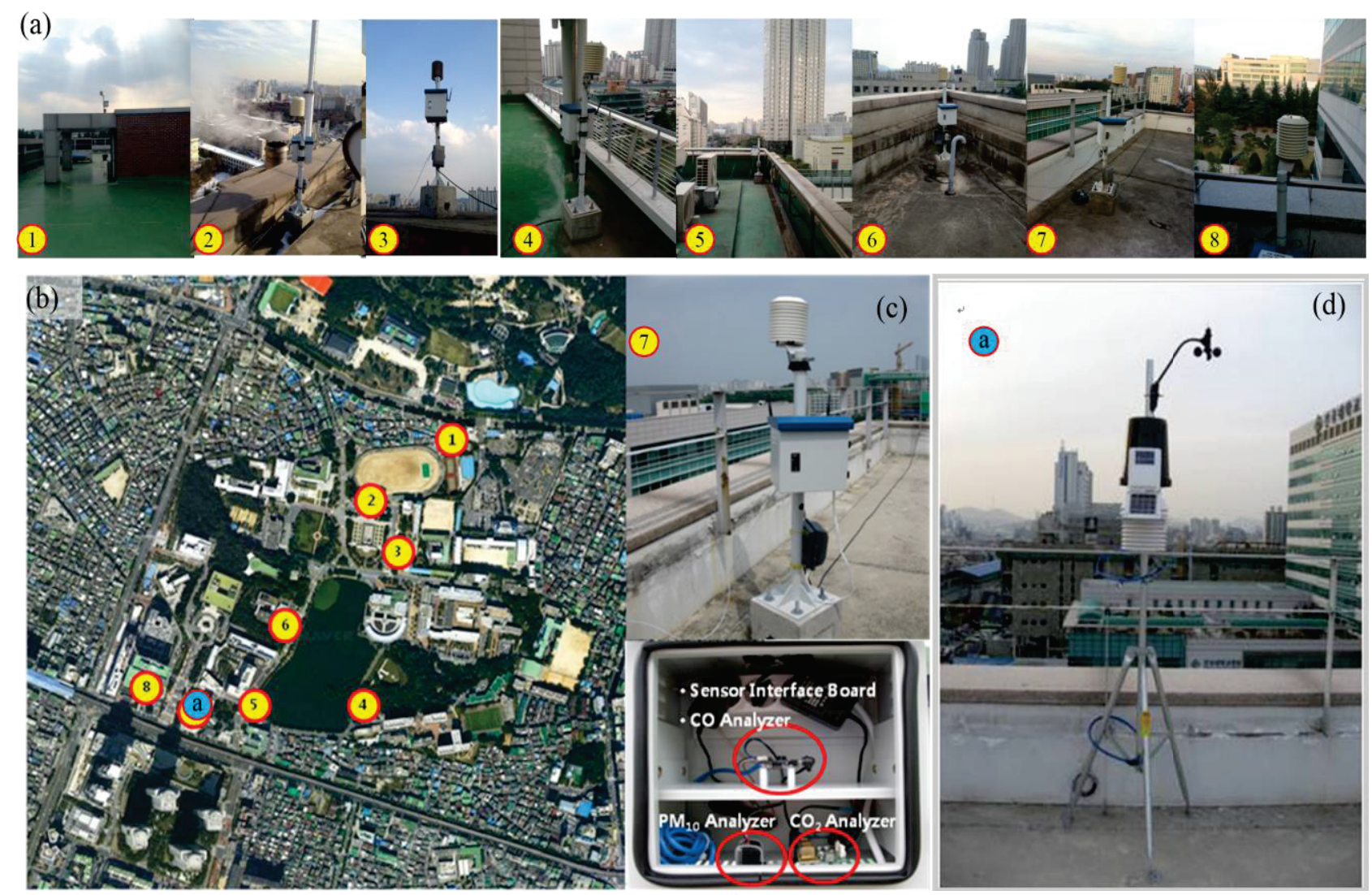

Figure 6. USN monitoring stations and AWS: (a) Installed USN monitoring station at the KUC domain; (b) Spatial locations of the monitoring stations; (c) sensors installed at USN sensor monitoring site 7. A commercially available CO sensor (GS-02A, NIDS Co.), non-dispersive infrared (NDIR) $\mathrm{CO}_{2}$ sensor (SH-300-DC, SOHA TECH Co.), Dust sensor (PSX-01E, NIDS Co.) are installed at eight USN monitoring stations, and (d) Installed AWS monitoring station. 


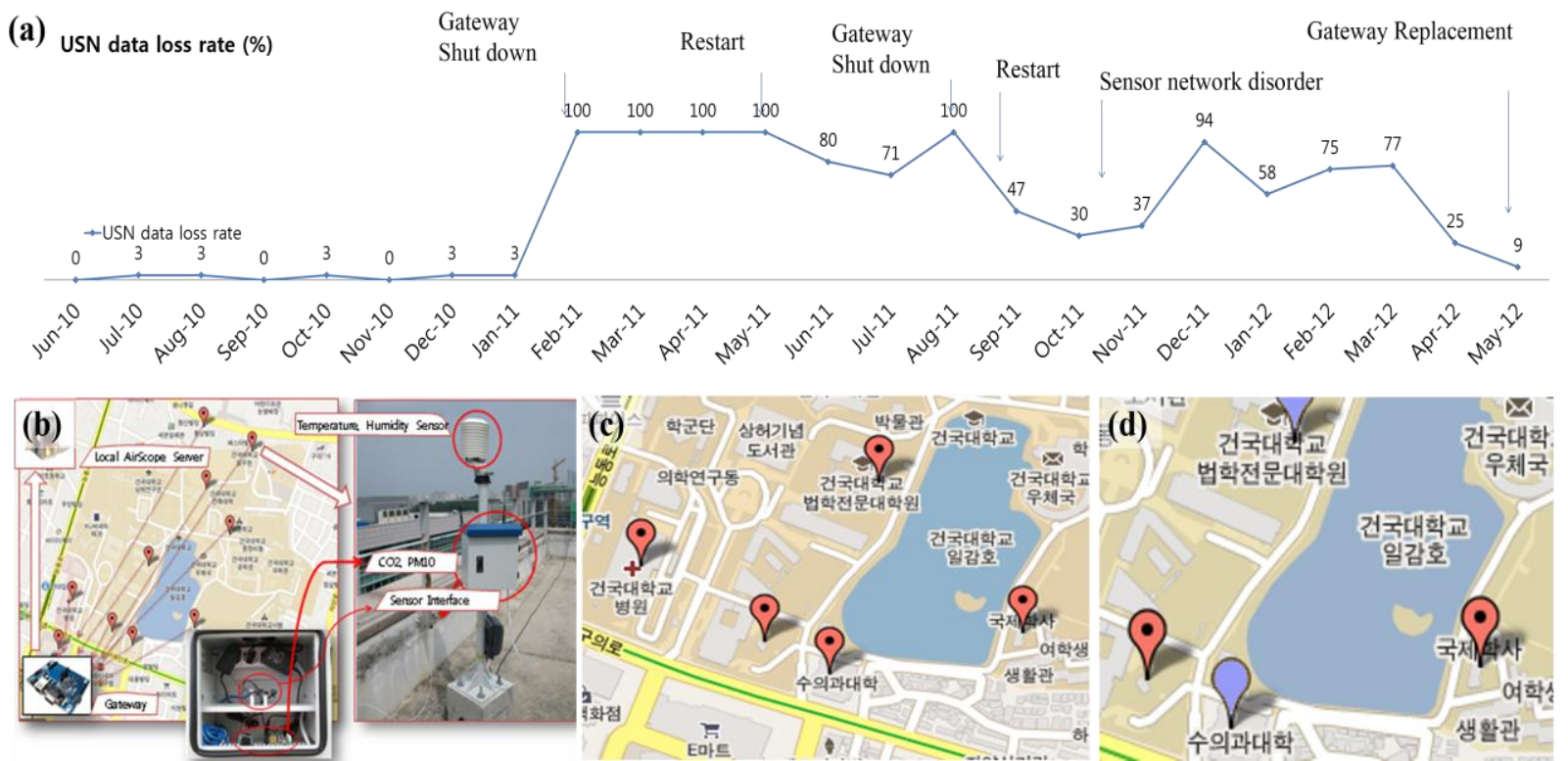

Figure 7. AirScope data management failure: (a) Monthly USN sensor data loss rate of the AirScope system. USN monitoring station wireless data transfer failure caused by (b) the Gateway disorder or (c) the Zigbee disorder in USN monitoring station (blue place mark).

Figure 8 shows the data for the temperature, humidity, and $\mathrm{CO}_{2}$ measured at 8 monitoring sites. Diurnal variations in temperature and humidity (Figure 8(a) and (b)) are very similar with each other. In the case of $\mathrm{CO}_{2}$ (Figure 8(c)), the concentration levels vary among the different monitoring sites, but the patterns are similar. It shows that the monitoring of $\mathrm{CO}_{2}$ using the sensors was valid.

To understand and improve the reliability of the sensor outputs, the temperature and humidity data between the USN monitoring station's sensor and the AWS installed were compared at site 7 during a 6-month operational period from July to December 2009. As illustrated in Figure 9(a) and (b), the variations in temperature and humidity show good agreement between sensor and AWS data. The correlations between the AWS and sensor data have high coefficients (temperature with $\mathrm{R}^{2}=0.9875$ and humidity with $\mathrm{R}^{2}=0$. 9567).

Table 3. The Meteorological Sensor Specifications of USN and AWS

\begin{tabular}{lll}
\hline Category & USN & AWS \\
\hline Temperature $\left({ }^{\circ} \mathrm{C}\right)$ & Range: $-40 \sim 123.8{ }^{\circ} \mathrm{C}$ & Range: $-40 \sim 65{ }^{\circ} \mathrm{C}$ \\
& Resolution: $0.01{ }^{\circ} \mathrm{C}$ & Resolution: $0.1{ }^{\circ} \mathrm{C}$ \\
& Accuracy: $\pm 0.4{ }^{\circ} \mathrm{C}$ & Accuracy: $\pm 0.5{ }^{\circ} \mathrm{C}$ \\
Humidity $(\%)$ & Range: $0 \sim 100 \%$ & Range: $0 \sim 100 \%$ \\
& Resolution: $0.03 \%$ & Resolution : $1 \%$ \\
& Accuracy: $\pm 3 \%$ & Accuracy : $\pm 4 \%$ \\
Carbon dioxide & Range: $0 \sim 3,000 \mathrm{ppm}$ & \\
$\left(\mathrm{CO}_{2}\right)$ & Resolution: $1 \mathrm{ppm}$ & \\
& Accuracy: $\pm 2 \mathrm{ppm}$ & \\
\hline
\end{tabular}
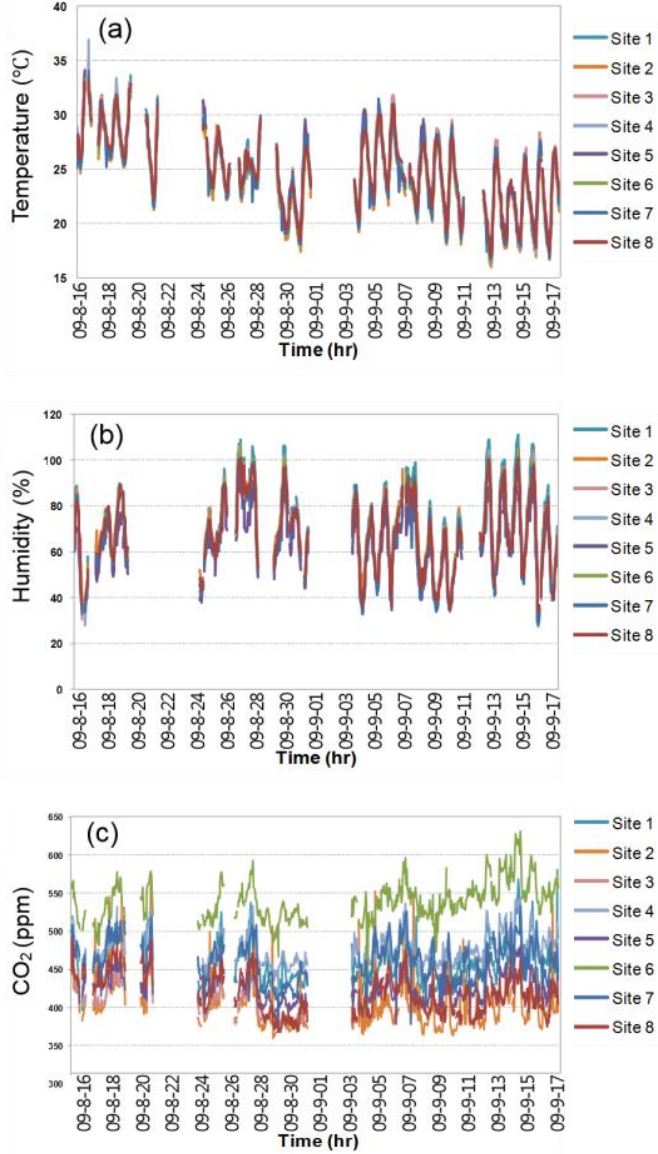

Figure 8. Data for sensor validation in the KUC domain: (a) temperature; (b) humidity; (c) $\mathrm{CO}_{2}$. 

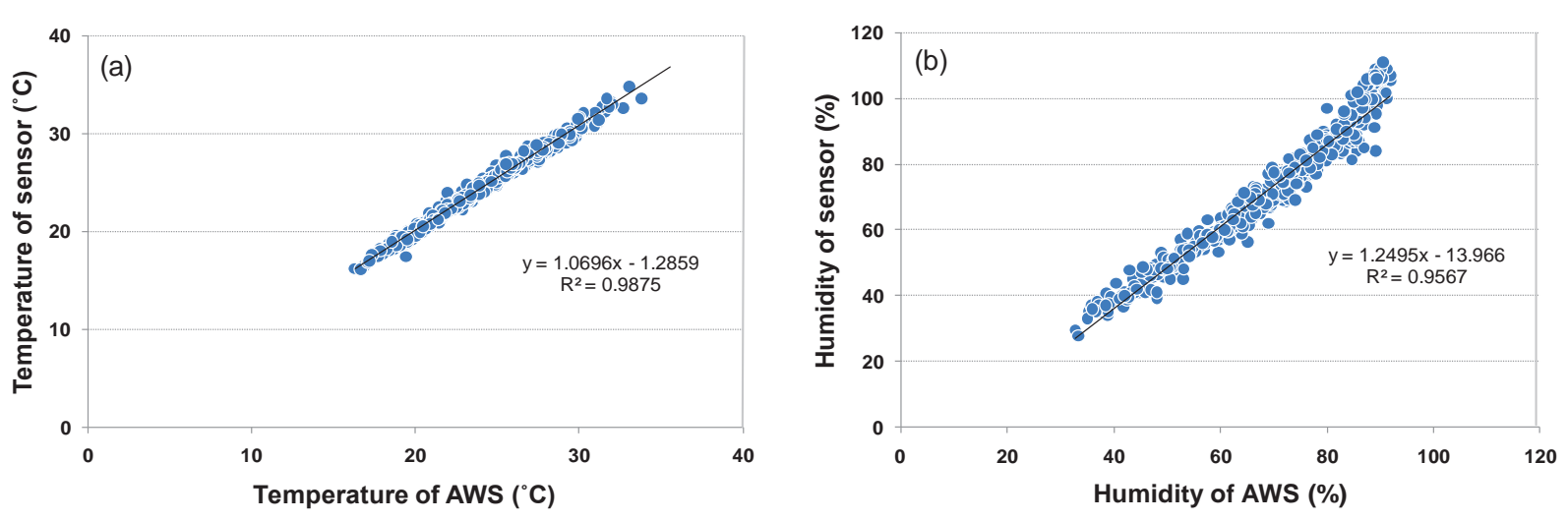

Figure 9. Correlations between sensor and AWS data: (a) temperature; (b) humidity.
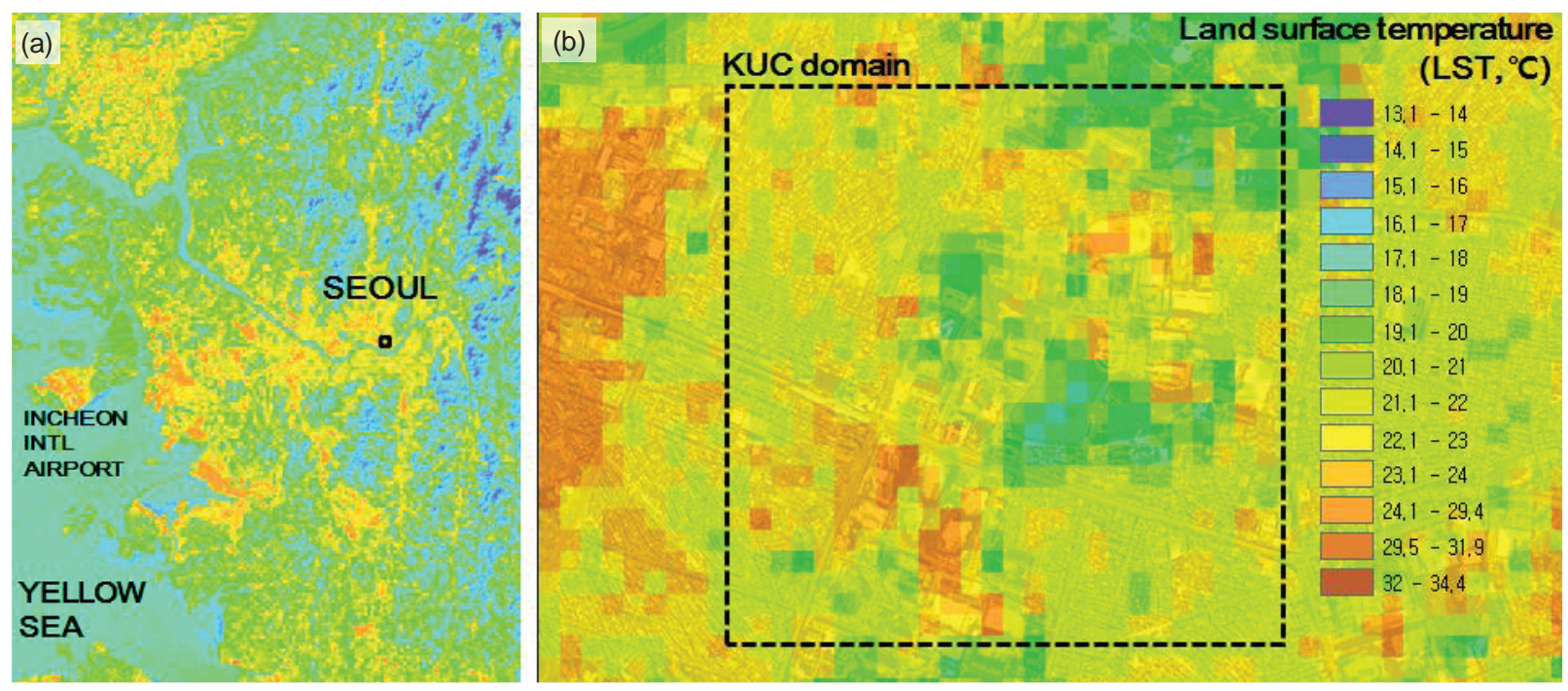

Figure 10. Distribution of land surface temperature: (a) in Seoul; (b) in KUC domain and its surroundings.

In addition to the data validation between sensor and AWS data, validation of meteorological sensor data using satellite-based land surface temperature measurements was also performed. The thermal infrared band of a satellite sensor (Landsat 7 ETM+) image acquired on September 23, 2000 was used in this study. Before conversion of the thermal band to temperature, thermal atmosphere correction was carried out to remove the effects of the atmosphere in the thermal region. This was possible with the thermal correction module for EN VI v. 4.2 by using both thermal bands (bands 61 and 62). The corrected thermal band data were converted to the digital numbers from at-satellite radiance. Lastly, the radiance was converted to surface temperature using the Landsat-specific estimate of the Planck curve (Chander and Markham, 2003). Fig. 10 shows the spatial distribution of land surface temperature (LST) in the KUC domain. The LST ranges from $17.2^{\circ} \mathrm{C}$ to $26.1^{\circ} \mathrm{C}$ (mean of $21.7^{\circ} \mathrm{C}$ and standard deviation of $1.2^{\circ} \mathrm{C}$ ). The surface temperatures in built-up areas range from 21.5 to $26.1{ }^{\circ} \mathrm{C}$, especially in commercial areas. The lower temperature zones are seen in the surroundings of the university area because of vast green areas and open spaces. The Landsat 7
ETM+ images could be a good source of inter-comparison. However, it is uneasy to use them as effective comparison sources for virtual sensors because of their limitation on temporal resolution for this study. Also, Landsat 7 ETM+ image indicates land surface temperature (LST), not an air temperature which is necessary for this work.

\subsection{CFD-based Virtual Sensor Implementation}

In order to fill in the missing points across the sensor network monitored area and to fill out missing sensors for criteria air pollutants (i.e. $\mathrm{PM}_{10}$ and $\mathrm{CO}$ ), the virtual sensor technique was applied by assuming that the CFD modeling outputs are the same as the pollutant monitoring data (e.g., $\mathrm{PM}_{10}$ ) from real sensors. Micro-scale air quality modeling was conducted under the assumption that high concentrations of $\mathrm{PM}_{10}$ exist owing to a fire accident in a building located in the eastern part of KUC domain. Figure 11 presents the simulation results using the CFD model. Dispersion of air pollutants was well-simulated with the passage of time and the influences of high-rise buildings on prevailing wind and fine scale curves could be identified. 

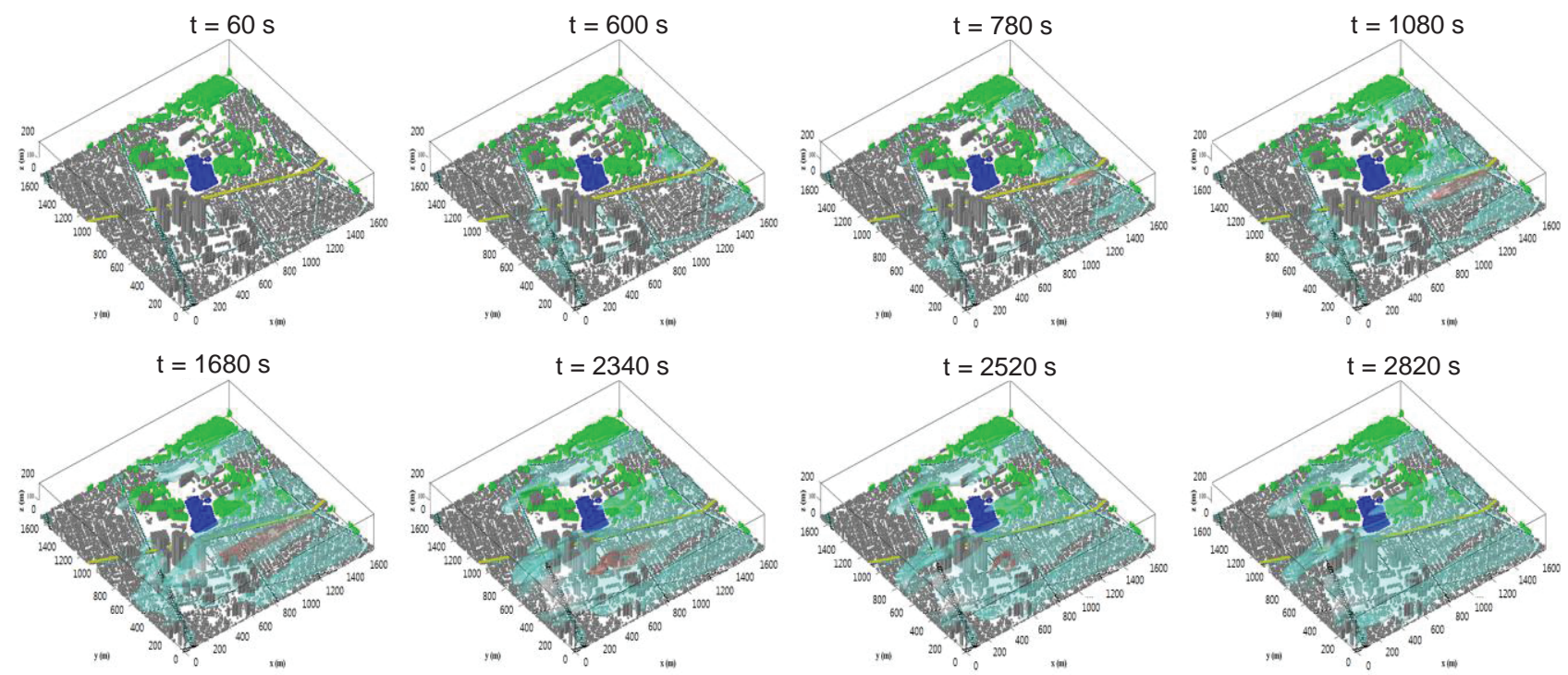

Figure 11. Simulation of a fire event using the CFD model.

(a)

\begin{tabular}{|c|c|c|c|c|c|}
\hline CFD_ID & $\mathrm{CO}$ & NO & PM & so & vo \\
\hline 1 & 4.17 & 4.17 & 4.17 & 4.17 & 4.17 \\
\hline 2 & 8.33 & 8.33 & 8.33 & 8.33 & 8.33 \\
\hline 3 & 13.48 & 13.48 & 13,48 & 13.48 & 13.48 \\
\hline 4 & 21.19 & 21.19 & 21.19 & 21.19 & 21.19 \\
\hline 5 & 28.13 & 28.13 & 28.13 & 28.13 & 28.13 \\
\hline 6 & 34.53 & 34.53 & 34.53 & 34.53 & 34.53 \\
\hline 7 & 40,05 & 40.05 & 40.05 & 40,05 & 40,05 \\
\hline 8 & 43.85 & 43.85 & 43.85 & 43,85 & 43.85 \\
\hline 9 & 46.18 & 46.18 & 46.18 & 46.18 & 46.18 \\
\hline 10 & 10.00 & 10,00 & 10.00 & 10.00 & 10.00 \\
\hline 11 & 11.00 & 11,00 & 11,00 & 11.00 & 11,00 \\
\hline 12 & 12.00 & 12,00 & 12.00 & 12,00 & 12,00 \\
\hline 13 & 10,84 & 10.84 & 10.84 & 10.84 & 10.84 \\
\hline 14 & 14.00 & 14.00 & 14.00 & 14.00 & 14.00 \\
\hline 15 & 15.00 & 15.00 & 15.00 & 15.00 & 15.00 \\
\hline
\end{tabular}

(b)

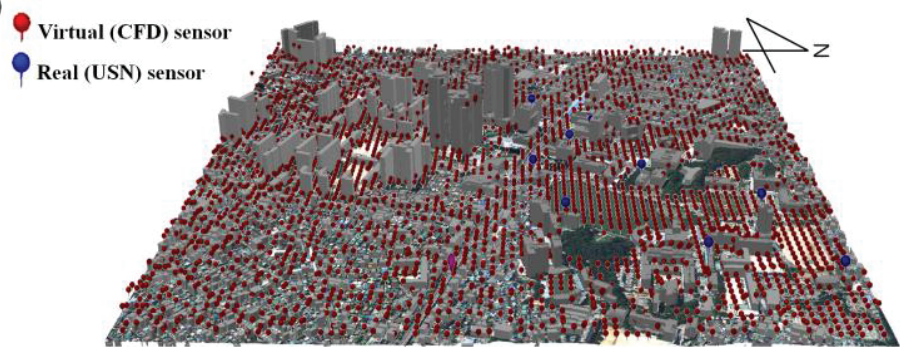

Figure 12. Virtual sensor extraction and integration with USN sensors: (a) Five virtual sensor attributes were extracted from the CFD model; (b) Visual integration of virtual sensor and real sensor on the 3D GIS. 3,625 point have been culled from 5,625 points $\left(75 \times 75,1^{\text {st }}\right.$ vertical layer of CFD model) to exclude building area.
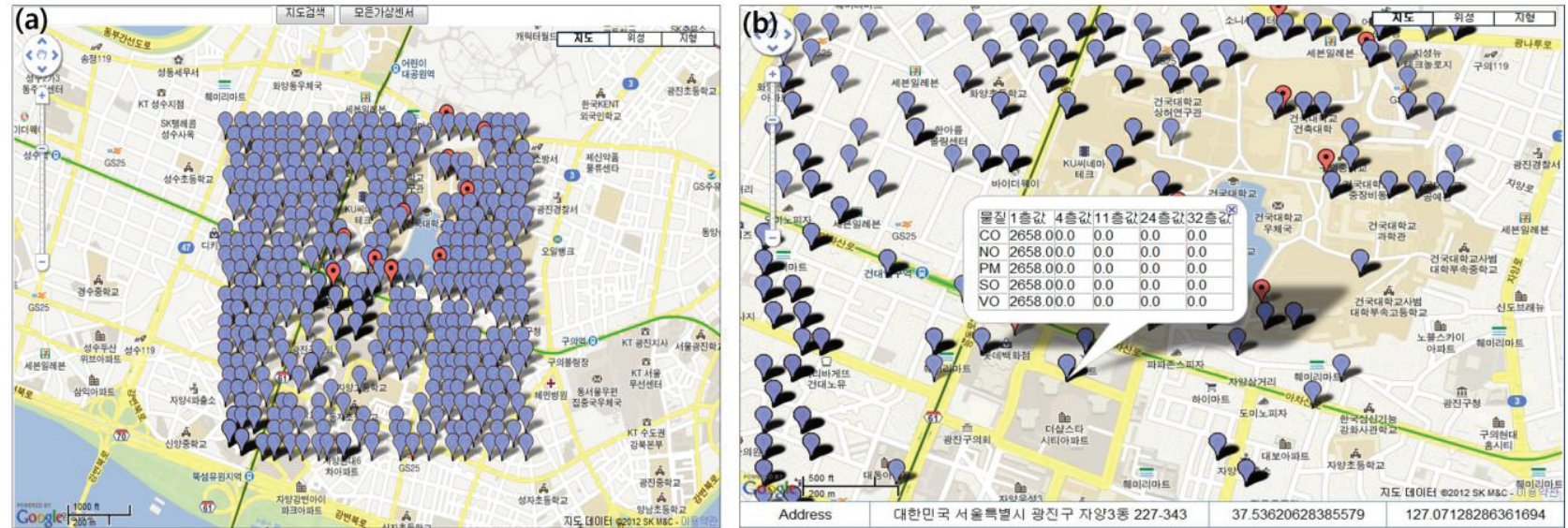

Figure 13. KUC testbed sensor map service on Google Map API: (a) Real sensors of USN monitoring stations and virtual sensors are integrated for web map service. Real sensors displayed as red place mark and virtual sensors are displayed as blue, which are supported by Google MAP API; (b) Users can see air quality concentration values of five criteria pollutants, where human are living, with pop-up window when they select blue place mark on the Google Map.

(http://117.16.149.119:8080/AirscopePortal/menu/sensor/pro/sensormap.jsp).

The virtual sensors are useful for providing micro-scale air quality and meteorological information in areas where mo- nitoring stations cannot provide coverage. In order to improve the usefulness of the virtual sensors, the quality of the data th- 
(a)

(b)
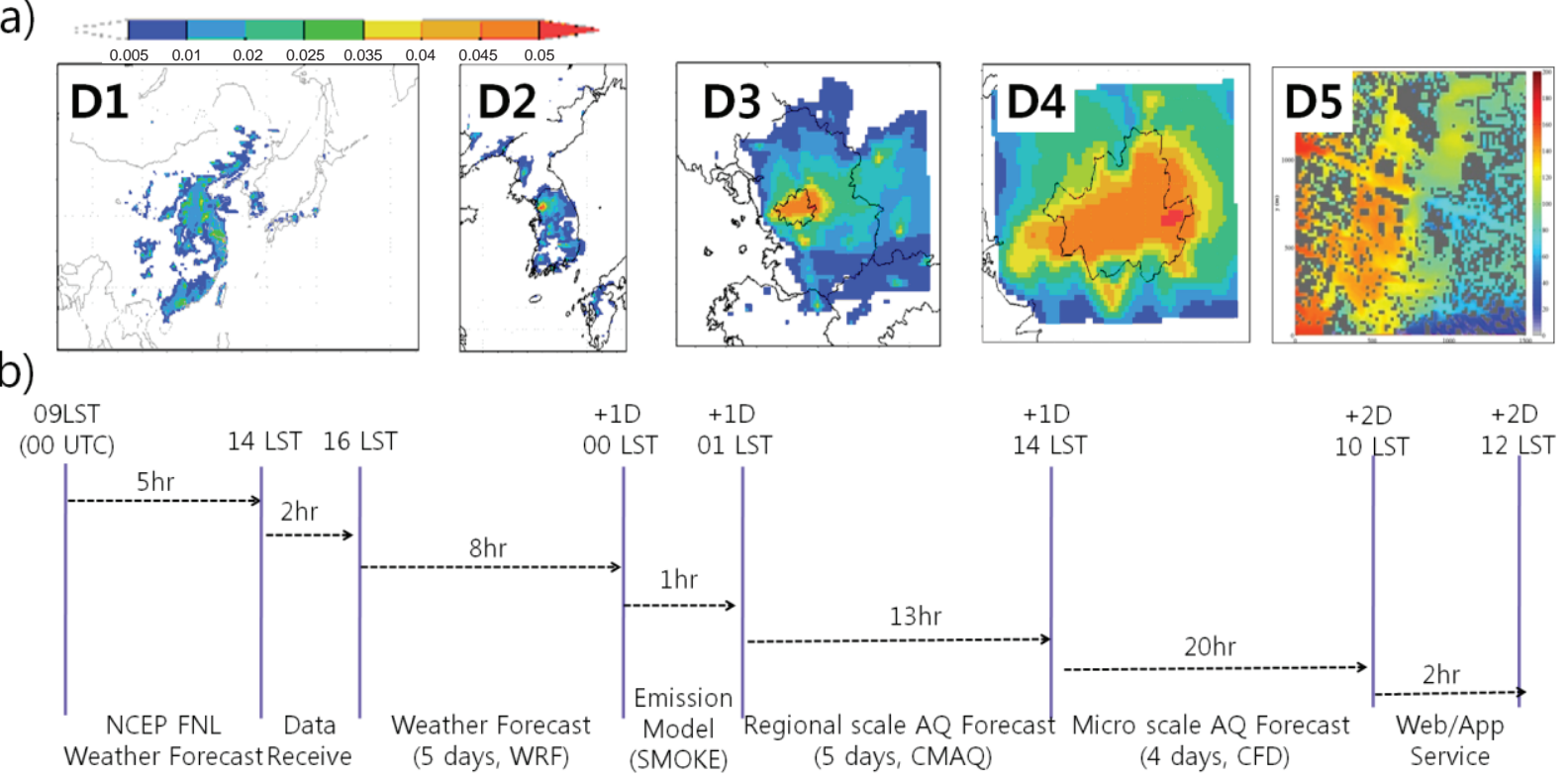

Figure 14. Five air quality modeling domains (Grid resolution; D1: 27 km, D2: 9 km, D3: 3 km, D4: 1 km, D5: 20 m) applied in this study (a) and air quality modeling and post-processing time schedule of the current MAMS system for predictive air quality service (b).

ey generate should be evaluated by comparing virtual sensor data with real sensor data, because the quality of the virtual sensors is still questionable. However, for the purposes of this study, the virtual sensors will achieve enough quality and will be implemented with the MAMS for the visualization of an improved air quality management system. Additionally, GIS database and 3-D building models can help to enhance the understanding of air pollution phenomena at high spatial/temporal resolution.

In this study, virtual sensors were designated to be located at 556 sites in the KUC domain under the assumption that real sensors will be installed in the same locations when available. As seen in Figure 13, integrated VSN-USN sensor system has a potential synergy because it compensates the limitations of USN system. Web based air quality service can not only cover a spatially and vertically interested locations but also provide un-monitored air quality information by virtual sensor technique such as $\mathrm{NO}_{2}$.

As Wilson (1997) quoted, virtual sensing technology can provide 1) improved control by providing virtual measurements, 2) predictive capability, 3) continuous output from periodic real measurements, 4) provide robustness to physical sensor failure. It is also true to our micro-scale air quality virtual sensor network framework. Though, up to now, MAMS air quality service does not include forecasting because of its low reliability of virtual sensor values, current system and process make it possible to forecast more than two days (Figure 14). In addition, we can provide a more reliable micro-scale air quality information services by integrating all available virtual sensors by compensating each sensor's defects. Remote sensing images with high spatial and spectral resolution will cover wide area air quality. In a near future, more reliable vir- tual sensors will come from remotely sensed images, from CFD-based micro-scale air quality model and low-cost, highdensity real sensor. These will be major components of the integrated VSN-USN air quality services.

\subsection{Applications of MAMS for Mobile Air Quality Services}

The ultimate purpose of this research is to develop futuristic air quality services that could be useful for citizens. New virtual sensor objects are produced every five minutes from CFD-generated output and transferred to the AirScope Server for web and mobile service for MAMS users. However, the air quality information from both real and virtual sensors needs to be collected and supplied at high speeds in order to provide useful information. The data should be also provided to the citizens in a location-based, user-friendly form. The information over mobile platforms is therefore very important for such services. Hence, in this study, we developed the MA MS application (MAMS app) in support of mobile information services, together with the MAMS application for the large platform (Woo et al., 2010). Figure 15 shows the mobile platform air quality service framework and relating MAMS app services. As seen in Figure 15(a), currently, mobile air quality services of MAMS are now available based on the communication framework between the MAMS management server and mobile app user interfaces. Users can request and get a service such as real time air quality service of real sensor or virtual sensor, daily air quality statistics in spite of limited service area (KUC domain) and poor validation of the air quality. MAMS mobile app users can obtain air quality services and related information such as sensor location and meteorological information (Figure 15(c)). In addition, with help of the virtual 
(a)

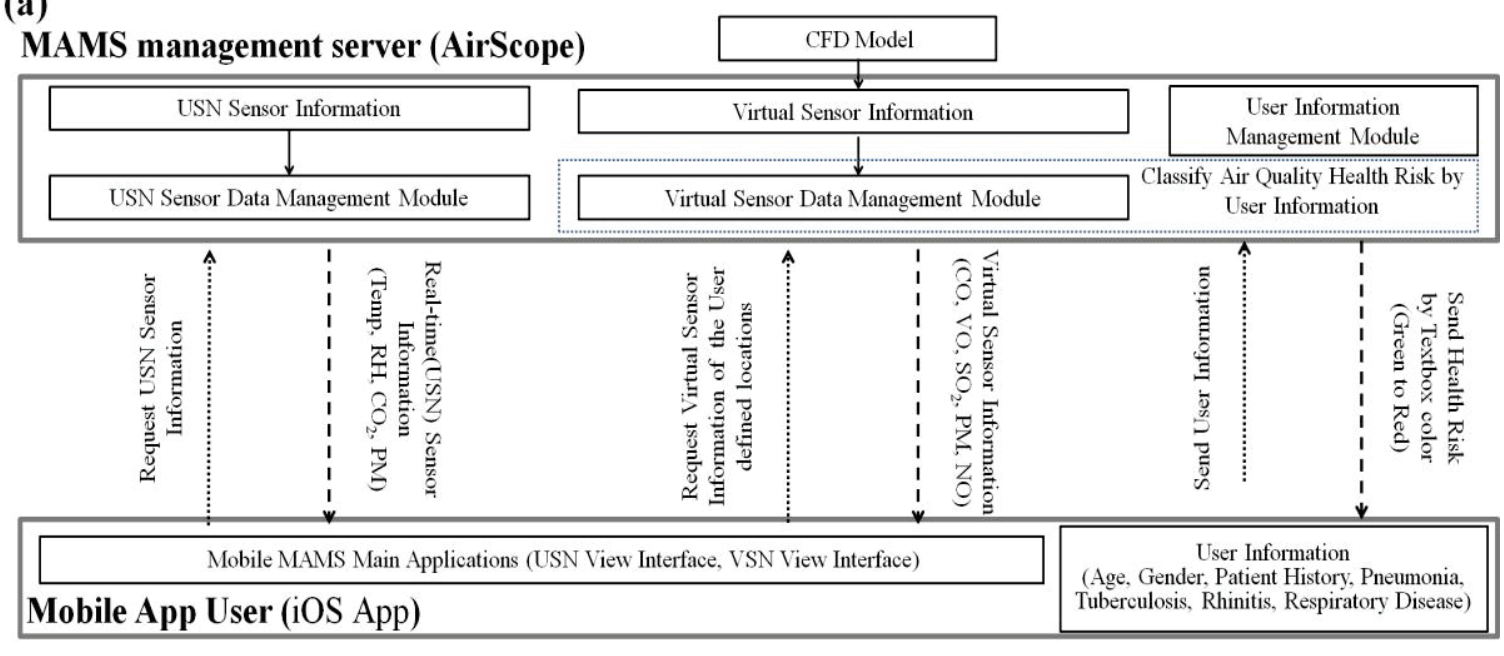

(b)

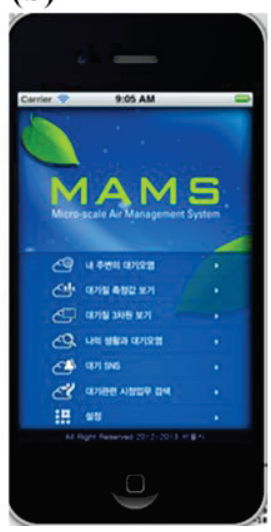

(c)

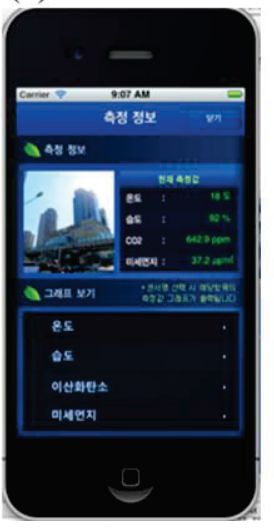

(d)

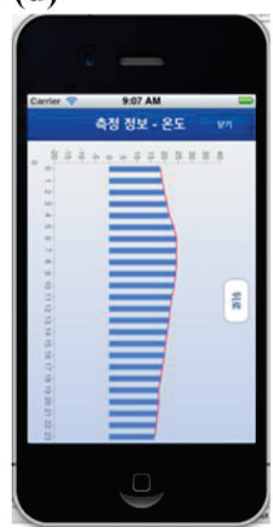

(e)

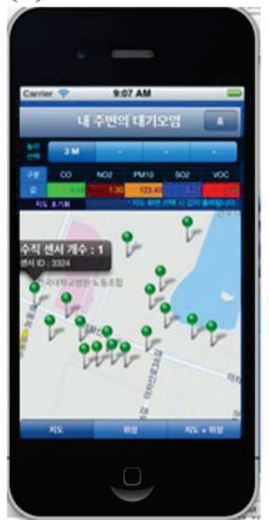

(f)

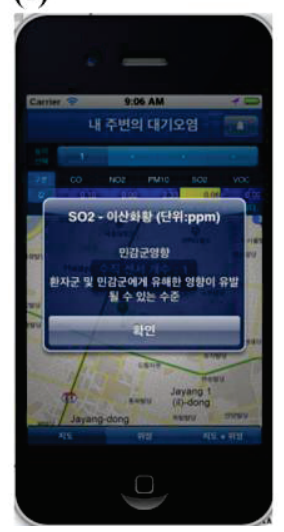

Figure 15. Smartphone based mobile air quality services of the MAMS (iOS): (a) Communication interface between the MAMS management server and mobile app user; (b) Main window of the MAMS mobile app; (c) USN sensor location and measured air quality information; (d) User can see the sensors one hour average graph chart per day; (e) Virtual sensor place mark and relating sensor/health risk information (textbox color) can be seen in KUC testbed when user selects location of interest by finger; (f) Health risk alarm message pop up when user is located at the hazardous area.

sensors, users receive the services using a densely distributed virtual sensor network, and hence, they can obtain information for their precise location. The MAMS system could provide the service at a relatively fast rate because it does not have to deal with a tremendous amount of full modeling output (i.e., 556 vs. 1.7 million data points). CFD-based virtual sensors, therefore, can be a cost effective alternative for a wide range of MAMS services such as SMA (Figure 15(c)). The benefit of the mobile MAMS app is to improve the public health risk management of urban citizens, especially for sensitive groups like the children and the elderly.

The mobile app based VSN-USN integrated mobile air quality service potentially expands applicable micro scale air quality service domain. USN sensor service can provide current time air quality information from several monitoring station. But integrated VSN-USN sensor system can provide not only spatially and temporally dense micro scale air quality information but also more additional scientific information to the user such as sources of the emissions and/or "causes and effects" of changes in air quality. This kind of information may lead to change people's behavior. By having access to

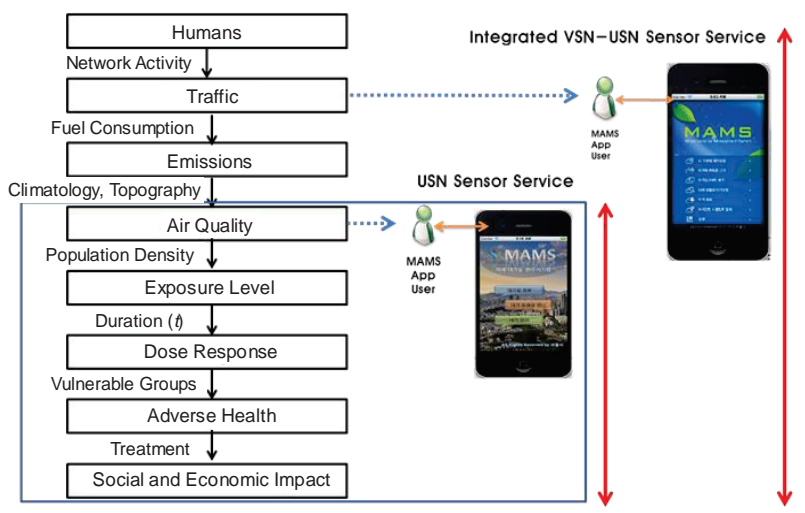

Figure 16. Applicable service domain of USN sensor service and integrated VSN-USN sensor service based on the adverse health impact chain (Ma et al., 2008). 
user location-based air pollution, air quality information and air quality risk information on time, they know exactly what is happen around their residential area and then can take protective actions for themselves or their caregivers. For example, they can move their home away from the emission source area. They can also provide feedback of their environmental situation and/or opinions through social networking services (SNSs), such as Facebook or Twitter.

Up to now, validation of virtual senor is unsolved issue and many scientific researches should follow to achieve this. Although, only a limited validation performed in this study because of the low sensor reliability, with development of real sensor and virtual sensor technology, proposed system will draw people's smart behavior for their health protection.

\section{Conclusions and Future Works}

In this paper, many insufficiently validated sources such as electronic sensor and CFD model were used as an input to produce micro scale air quality services as a proof of concept. We developed a framework for a micro-scale air quality management system (monitoring and modeling system) called MAMS. A $1.5 \times 1.5 \mathrm{~km}$ domain around Konkuk University was selected as a testbed. The developed system utilizes a US$\mathrm{N}$ for micro-scale sensor management and processes a huge amount of real-time sensor data. Moreover, a CFD-based air quality modeling system was developed and included in the MAMS framework. In order to overcome the limitations of the sensor network for real-world applications, the concept of virtual sensors combined with the CFD-based air quality modeling system was developed. Based on the information provided by the virtual sensors, a futuristic air quality service of the MAMS application for a mobile platform was developed to allow users to easily obtain air quality services and provide feedback through SNSs.

In the future, the system's application will be extended by 1 ) adding other sensors (i.e., a $\mathrm{PM}_{10}$ counter) at the monitorring sites, 2) expanding the testbed and monitoring domain, and 3) linking the CFD model with a regional scale model and integrating CFD-based virtual sensors into the MAMS. Finally, we will also build a web-based information portal and mo- bile platforms of the MAMS app to allow citizens to acc- ess the information whenever needed. In addition, most of all, more significant pollutants (such as $\mathrm{NO}_{\mathrm{x}}, \mathrm{SO}_{2}, \mathrm{VOCs}, \mathrm{O}_{3}$ ) refinement of the CFD methodology and a full validation exercise should be followed.

Acknowledgement. This study was supported by the Korea Ministry of Environment by 'The Eco-Innovation project (411-113-013)' and the Korea Meteorological Administration Research and Development Program under Grant CATER 2012-6123. The authors are definitely indebted to the three anonymous reviewers.

\section{References}

Botts, M., and Robin, A. (2007). OpenGIS sensor model language (SensorML) implementation specification. Open Geospatial Consort..

Carotta, M. C., Martinelli, G., Crema, L., Malagù, C., Merli, M., Ghiotti, G., and Traversa, E. (2001). Nanostructured thick-film gas sensors for atmospheric pollutant monitoring: Quantitative analysis on field tests. Sensors Actuators B: Chem., 76(1), 336-342. http://dx.doi.org/10.1016/S0925-4005(01)00620-7

Ciciriello, P., Mottola, L., and Picco, G. P. (2006). Building virtual sensors and actuators over logical neighborhoods. Proc. of the International Workshop on Middleware for Sensor Networks, Melbourne, pp. 19-24. http://dx.doi.org/10.1145/1176866.1176870

Chander, G., and Markham, B. (2003). Revised Landsat-5 TM radiometric calibration procedures and postcalibration dynamic ranges. IEEE Trans. Geosci. Remote Sens., 41(11), 2674-2677. http://dx. doi.org/10.1109/TGRS.2003.818464

Cox, S. (2011). Observations and Measurements - XML Implementation. Open Geospatial Consort..

Dailey, D. J., and Cathey, F. W. (2006). The Automated Use of Un-calibrated CCTV Cameras as Quantitative Speed Sensors Phase 3, Washington State Transportation Center 635.1.

Elliott, S. J., and David, A. (1992). A virtual microphone arrangement for local active sound control. Proc. of the 1st International Conference on Motion and Vibration Control, pp. 1027-1031.

Guttikunda, S. K., Carmichael, G. R., Calori, G., Eck, C., and Woo, J. H. (2003). The contribution of megacities to regional sulfur pollution in Asia. Atmos. Environ., 37, 11-22. http://dx.doi.org/10.1016/ S1352-2310(02)00821-X

Hardy, N., and Maroof, A. A. (1999). ViSIAr - A virtual sensor integration architecture. Robotica, 17(6), 635-647. http://dx.doi.org/10. 1017/S0263574799001915

\section{Appendix}

Monitoring Stations of South Korea (2000)

\begin{tabular}{|c|c|c|c|c|}
\hline \multirow{2}{*}{ Monitoring Network Type } & \multirow{2}{*}{ Monitoring Parameters } & \multicolumn{3}{|c|}{ Number of the site } \\
\hline & & Sub sum & MOE & Local autonomous \\
\hline Local AQ measurement & $\mathrm{SO}_{2}, \mathrm{NOx}, \mathrm{O}_{3}, \mathrm{CO}, \mathrm{PM}_{10}$, Meteorological parameter & 182 & 5 & 177 \\
\hline Roadside measurement & $\mathrm{SO}_{2}, \mathrm{NOx}, \mathrm{O}_{3}, \mathrm{CO}, \mathrm{PM}_{10}$, Meteorological parameter & 18 & - & 18 \\
\hline Acid Rain & pH, Precipitation, Electric conductivity, Ion & 32 & 31 & 1 \\
\hline National background AQ & $\mathrm{SO}_{2}, \mathrm{NOx}, \mathrm{O}_{3}, \mathrm{CO}, \mathrm{PM}_{10}$, Meteorological parameter & 5 & 5 & - \\
\hline Local background AQ & $\mathrm{SO}_{2}, \mathrm{NOx}, \mathrm{O}_{3}, \mathrm{CO}, \mathrm{PM}_{10}$, Meteorological parameter & 9 & 9 & - \\
\hline heavy metal & $\mathrm{Pb}, \mathrm{Cd}, \mathrm{Cr}, \mathrm{Cu}, \mathrm{Mn}, \mathrm{Fe}, \mathrm{Ni}$ & 39 & - & 39 \\
\hline Atm. hazardous particles & VOCs (13), PAH(7) & 16 & 16 & - \\
\hline Photochemical pollutants & VOCs (56) & 17 & 8 & 9 \\
\hline Visibility range & Visibility (Scattering coefficient) & 4 & - & 4 \\
\hline Earth atmosphere & $\mathrm{SO}_{2}, \mathrm{NO}_{2}, \mathrm{CH}_{4}$ (CFCs) & 1 & 1 & - \\
\hline Total & & 323(69) & $75(37)$ & $248(56)$ \\
\hline
\end{tabular}


Hu, G. R., Khoo, H. S., Goh, P. C., and Law, C. L. (2003). Development and assessment of GPS virtual reference stations for RTK positioning. J. Geodesy, 77(5-6), 292-302. http://dx.doi.org/10. 1007/s00190-003-0327-4

Kamionka, M., Breuil, P., and Pijolat, C. (2006). Calibration of a multivariate gas sensing device for atmospheric pollution measurement. Sensors Actuators B: Chem., 118(1), 323-327. http://dx.doi.org/10.1016/j.snb.2006.04.058

Kim, J. J., and Baik, J. J. (2010). Effects of street-bottom and building-roof heating on flow in three-dimensional street canyons. Adv. Atmos. Sci., 27(3), 513-527. http://dx.doi.org/10.1007/s00 376-009-9095-2

Liu, L., Kuo, S. M., and Zhou, M. (2009). Virtual sensing techniques and their applications. Proc. of the International Conference on Networking, Sensing and Control, Okayama, 31-36. http://dx.doi. org/10.1109/ICNSC.2009.4919241

Ma, Y., Richards, M., Ghanem, M., Guo, Y., and Hassard, J. (2008). Air pollution monitoring and mining based on sensor grid in London. Sensors, 8(6), 3601-3623. http://dx.doi.org/10.3390/s806 3601

Mead, M. I., Popoola, O. A. M., Stewart, G. B., Landshoff, P., Calleja, M., Hayes, M., Baldovi, J. J., McLeod, M. W., Hodgson, T. F., Dicks, J., Lewis, A. , Cohen, J., Baron, R., Saffell, J. R., and Jones, R. L. (2013). The use of electrochemical sensors for monitoring urban air quality in low-cost, high-density networks. Atmos. Environ., 70, 186-203. http://dx.doi.org/ 10.1016/j.atmosenv.2012. 11.060

Moussafir, J., Olry, C., Nibart, M., and Albergel, A. (2013) Aircity, a very High-resolution 3D Atmospheric Dispersion Modeling Sys- tem for Paris. In 15th Int. Conf. on Harmonisation within Atmospheric Dispersion Modelling for Regulatory Purposes.

OECD (2000). Ancillary benefits and costs of greenhouse gas mitigation. Proc. of an IPCC Co-sponsored Workshop, 27-29 March 2000, Washington, DC., USA.

Streets, D. G., Carmichael, G. R., Amann, M., and Arndt, R. L. (1999). Energy consumption and acid deposition in Northeast Asia. Ambio, 28, 135-143.

Ung, A., Wald, L., Ranchin, T., Weber, C., Hirsch, J., Perron, G., and Kleinpeter, J. (2001). Satellite data forair pollution mapping over a city -Virtual stations, Proc. of the 21th EARSel Symposium, Observing Our Environment from Space: New Solutions for a New Millennium, Paris, France, pp. 147-151.

Wilson, E. (1997). Virtual Sensor Technology for Process Optimization. In Symposium on Computers and Controls in the metals Industry.

Woo, J. H., Kim, H. S., Lim, S. B., Kim, J. J., Lee, J., Ryoo, R., and Kim, H. (2010). AirScope: A micro-scale urban air quality management system. ICA3PP, (1), 520-527. http://dx.doi.org/10.1007/9 78-3-642-13119-6_45

Woo, J. H., Kim, H., Lim, S. B., Kim, J. J., Lee, J., Ryoo, R., Kim, H., and Minh, L. D. (2011). Constructing u-City of Seoul by future foresight analysis. Concurrency Comput. Pract. Exper., 23, 1114-1126. http://dx.doi.org/10.1002/cpe.1690

Yoo, S., Woo, J. H., Ryoo, R., Jung, B., Seo, J. S., Kim, J. J., Lim, S. B., and Kim, H. S. (2010). Development of a micro-scale air monitoring and modeling system for a urban district air quality management, EGU General Assembly Conference Abstracts, Vienna, 12, 7721 